\title{
Research on Optimal Design and Modal Analysis of the Frame
}

\author{
Kaifa Lian ${ }^{1}$, Bailin Fan ${ }^{1, *}$, Yuan Miao ${ }^{2}$ and Xueyang Zhu ${ }^{1}$ \\ ${ }^{1}$ School of Mechanical Engineering, University of science and technology Beijing, Beijing 100083, China \\ ${ }^{1}$ No. 30, Xueyuan Road, Beijing, Haidian District, China \\ ${ }^{2}$ Yuci District, Jinzhong City, Shaanxi Province, China \\ *Corresponding author
}

\begin{abstract}
Carry out the static analysis of the frame under different working conditions and put forward four kinds scheme of the improvement of the beam, longitudinal beam and traction plate. Besides, carry out the modal analysis of the frame, get the natural frequency and vibration mode of the frame, to provide the driver with a reliable theoretical basis to avoid the resonance.
\end{abstract}

Keywords-gooseneck type semi-trailer frame; static analysis; modal analysis; structural improvement; optimal design

\section{INTRODUCTION}

The design of the frame relies on the experience of practitioners generally in the actual design of the frame, although it has enough strength and rigidity, there is a waste of raw materials and the use of the loss, resulting in unnecessary economic costs. Analyze the static analysis of the frame under different operating conditions by use ANSYS software ${ }^{[1,2]}$, and put forward the scheme of the improvement, to optimize the weight of the frame farthest and reduce economic costs under the premise of meeting the requirements of the strength and stiffness.

ANSYS is a general finite element analysis software for large computer aided engineering with structure, heat, fluid, electromagnetic and integration. ANSYS mainly analyzes the response of the actual structure under loading stress, including the displacement and stress, according to the response we can know the state of the structure, and then determine whether the structure meets the requirements.

Modal analysis has a very wide range of practical value as a part of the dynamic analysis, also can help the designer to determine the natural frequency and mode shape thus help the structure to avoid resonance.

The semitrailer is always influenced by the road surface in the course of driving. It is necessary to carry out modal analysis for the optimal frame, to judge the model of the optimal frame whether can meet the safe driving on the bad road. In order to achieve the purpose of safe driving the drivers need to determine the natural frequency and vibration mode of the frame, providing the reliable theoretical basis for them to avoid the resonance of the frame.

\section{The Static ANAlysis OF The Frame}

\section{A. The Structural Analysis of the Frame}

A gooseneck type semitrailer is composed of 2 longitudinal beams whose cross section are I-shaped, with the length of $11250 \mathrm{~mm}$, the width of $840 \mathrm{~mm}$, the materials of T700, 18 beams whose cross section are groove, with the length of $2220 \mathrm{~mm}$, the materials of T700, and the towing pin eat, with the materials of Q345, the semitrailer can also bear the weight of $40 \mathrm{t}$. Besides we weld the beam the plate of the longitudinal beam together.

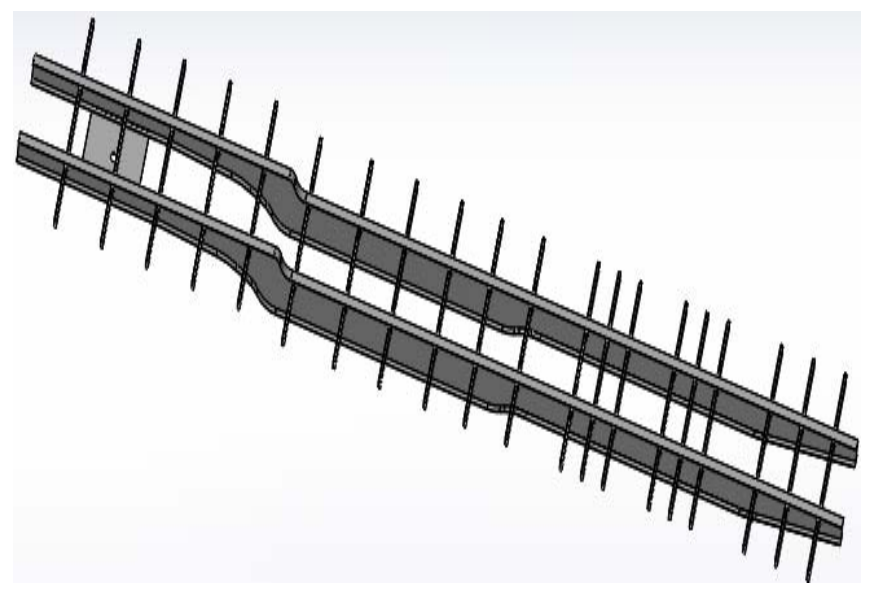

FIGURE I. THE 3D MODEL OF THE GOOSENECK TYPE SEMITRAILER FRAME.

\section{B. Mesh}

Using the mesh tool comes with ansys workbench 14.5 , to mesh the structure of the frame into elements; the structure of the frame has 245287 elements with the size of $50 \mathrm{~mm}$ and 519055 nodes.

\section{The Static Analysis of the Frame under Different Working Conditions}

The camion always has conditions of sharp brake, sharp turn and reverse in the rough pavement in the process of driving. Therefore, the static analysis [3 5] of the frame is mainly on the basis of the above conditions. 
TABLE I. THE STRESS ANALYSIS UNDER DIFFERENT WORKING CONDITIONS

\begin{tabular}{lcl}
\hline & $\begin{array}{c}\text { Maximum } \\
\text { stress }(\mathrm{MPa})\end{array}$ & $\begin{array}{c}\text { Place of } \\
\text { occurrence }\end{array}$ \\
\hline Static condition & 218.23 & $\begin{array}{l}\text { The beam web above } \\
\text { the towing pin seat }\end{array}$ \\
$\begin{array}{l}\text { The condition of } \\
\text { urgent turning }\end{array}$ & 228.81 & $\begin{array}{l}\text { The beam web above } \\
\text { the towing pin seat }\end{array}$ \\
$\begin{array}{l}\text { The condition of } \\
\text { emergency } \\
\text { breaking } \\
\text { The condition of } \\
\text { torsion }\end{array}$ & 221.31 & $\begin{array}{l}\text { The beam web above } \\
\text { the towing pin seat }\end{array}$ \\
& 240.68 & $\begin{array}{l}\text { The beam web above } \\
\text { the towing pin seat }\end{array}$
\end{tabular}

The maximum stress under the condition of torsion is far less than the allowable stress, according to the formula $[\sigma]=\sigma_{s} / n_{s}=443 \mathrm{MPa}[6]$, although the condition of torsion is the most dangerous among the above conditions of the table 1, therefore, it can be concluded that the frame has a large space for optimize. Considering the condition of torsion is the most dangerous, we take the condition of torsion as the only criterion for the check of the frame in the following improvement schemes.

\section{The Improvement Scheme of the Frame}

Make improvement [7, 8] of the longitudinal beam, beam and towing pin seat of the frame, and ensure that the frame gets the maximum degree of quantification under the premise of meeting the requirements of strength and rigidity.

TABLE II. THE CHANGE OF THE QUALITY UNDER DIFFERENT SCHEMES

\begin{tabular}{|c|c|c|c|}
\hline Different schemes & $\begin{array}{l}\text { Maximum } \\
\text { stress }\end{array}$ & $\begin{array}{l}\text { The quality } \\
\text { of the } \\
\text { frame }\end{array}$ & $\begin{array}{l}\text { The change of } \\
\text { the quality }\end{array}$ \\
\hline Original frame & 240Mpa & $1199 \mathrm{~kg}$ & $0 \mathrm{~kg}$ \\
\hline $\begin{array}{l}\text { Scheme } 1 \text { : reduce the } \\
\text { thickness of the web } \\
\text { of the beam }\end{array}$ & $265 \mathrm{Mpa}$ & $1101 \mathrm{~kg}$ & $98 \mathrm{~kg}$ \\
\hline $\begin{array}{l}\text { Scheme } 2 \text { : reduce the } \\
\text { area of traction pin } \\
\text { plate }\end{array}$ & 280Mpa & $1179 \mathrm{~kg}$ & $20 \mathrm{~kg}$ \\
\hline $\begin{array}{l}\text { Scheme } 3 \text { : reduced } \\
\text { the thickness of the } \\
\text { flange of the beam }\end{array}$ & 254Mpa & $1148 \mathrm{~kg}$ & $51 \mathrm{~kg}$ \\
\hline $\begin{array}{l}\text { Scheme } 4 \text { : reduce the } \\
\text { thickness of the web } \\
\text { and flange of } \\
\text { the beam }\end{array}$ & 340Mpa & $1048 \mathrm{~kg}$ & $151 \mathrm{~kg}$ \\
\hline
\end{tabular}

Conclusion: it can be seen that the scheme ${ }^{1 \times 9}$ meet the requirements of strength from table 2, but isn't significant in the aspect of optimize the weight of the frame. The scheme 4 that the longitudinal beam gets "downsizing" is more effectively in reducing the weight of the frame, and is the best scheme among above.

\section{MODAL ANALYSIS}

Make the modal analysis $[9,10]$ of the model of the frame in the scheme 4 of table 2. It is selected from the first 8 order to analyze the natural frequency and vibration mode of the frame, since the modal analysis of the frame is generally concentrated in the low order frequency. Table 3 is the natural frequency and mode shape of the frame, and also the mode change curve chart of the frame are from figure 1.

TABLE III. THE NATURAL FREQUENCY AND MODE SHAPE OF THE FRAME

\begin{tabular}{|c|c|c|}
\hline $\begin{array}{l}\text { Modal } \\
\text { order } \\
\end{array}$ & $\begin{array}{l}\text { Modal } \\
\text { frequency }\end{array}$ & Modal vibration mode \\
\hline 1 & 8.9739 & Lateral bending \\
\hline 2 & 15.897 & The reverse of gooseneck \\
\hline 3 & 18.381 & The reverse of gooseneck \\
\hline 4 & 19.295 & The reverse of gooseneck \\
\hline 5 & 27.650 & The bending of the beam \\
\hline 6 & 27.680 & The bending of the beam \\
\hline 7 & 27.763 & The torsion of the tail \\
\hline 8 & 27.775 & The bending of the beam \\
\hline
\end{tabular}

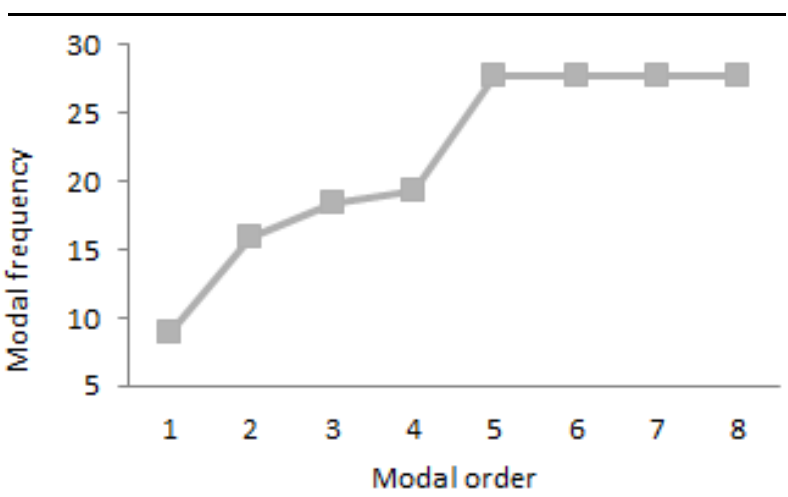

FIGURE II. The MODE CHANGE CURVE OF THE FRAME 


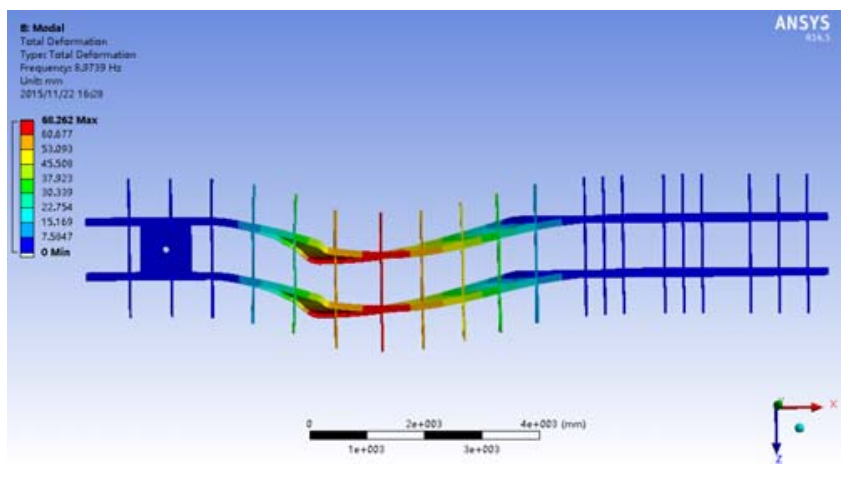

FIGURE III. THE FIRST ORDER MODE SHAPE

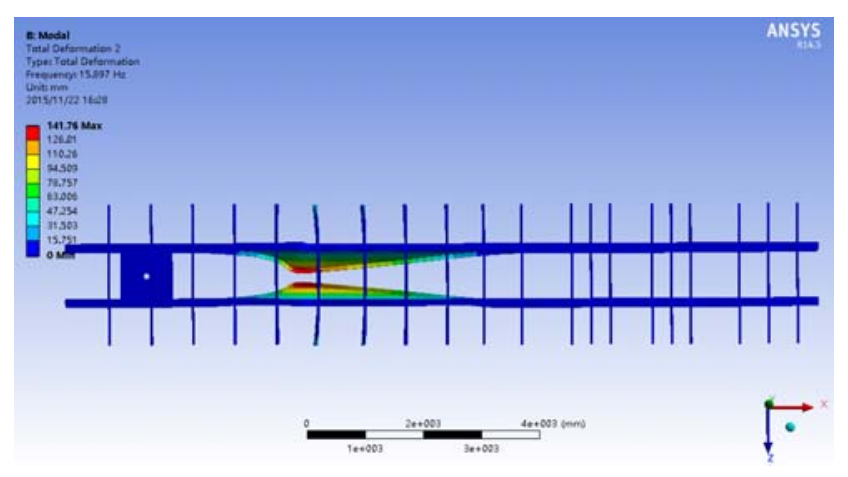

FIGURE IV. THE SECOND ORDER MODE SHAPE

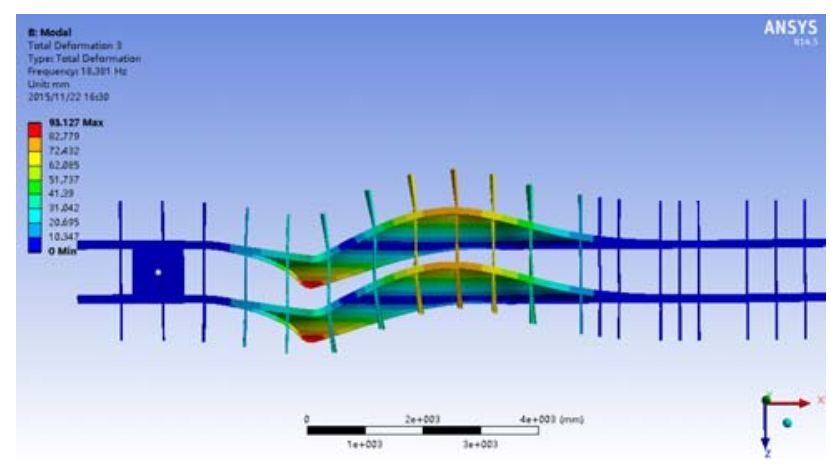

FIGURE V. THE THIRD ORDER MODE SHAPE

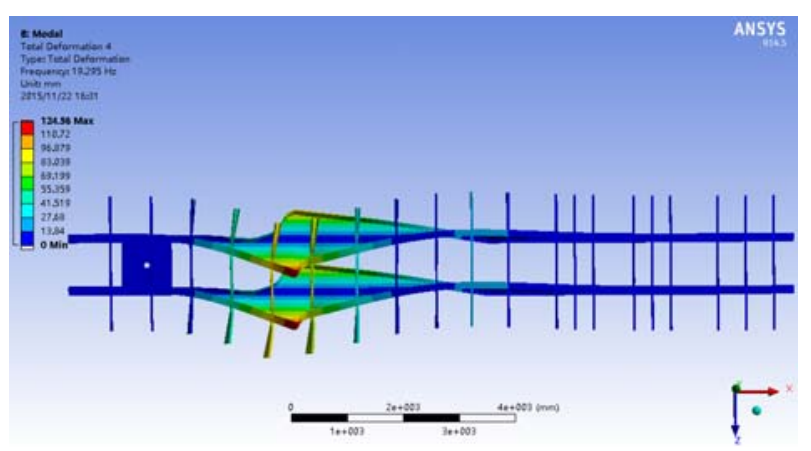

FIGURE VI. THE FOURTH ORDER MODE SHAPE

\section{CONCLUSIONS}

1) According to table 2 it can be seen that reduce the thickness of the web and flange of the longitudinal can effectively reduce the weight of the frame and reduce the economic cost under meet the requirements of strength and stiffness.

2) We can easily see that the modal frequency of the frame is flat from figure1, and there is no mutation phenomenon.

3) It is not difficult to see that the amplitude of the gooseneck of the frame is large from the top four modal graph of the frame, and it proves that the stiffness of the gooseneck is weaker than other parts of the frame, so the gooseneck of the frame needs to be further strengthened and improved.

4) The engine and suspension system have little effect on the vibration of the frame, for the natural frequency of the engine and the suspension system is generally between $1-3 \mathrm{mz}$, and the lowest natural frequency of the frame is even much higher than $3 \mathrm{~Hz}$. As we all know that the excitation frequency of the surface of the road in the vertical direction is generally below $20 \mathrm{Mz}$, the bending or torsion of the frame is in the horizontal direction contrarily, whose natural frequency is in the following $20 \mathrm{~Hz}$ limited only the first four mode shape of the frame, thus effectively avoiding the resonance of the frame.

\section{REFERENCES}

[1] Min Wu, Longfei Xie. The finite element analysis and simulation of ansys workbench [M]. Beijing: Electronic Industry Press.2014.

[2] Jinfeng Xu. ANSYS Workbench15.0 a completely self-taught [M]. Beijing: Electronic Industry Press.2014.09.

[3] Dejin Yu, Nan Chen. Finite element static analysis of the heavy semitrailer frame [J]. special purpose vehicle.2006.12.

[4] Jianquan $\mathrm{Xu}$, Jiandeng Su, Mingnian Chen. Finite element analysis of the flat type semi-trailer frame $[\mathrm{J}]$, Fujian University of Technology.2012.02.

[5] Cheng Lin, Sizhong Chen, Zhicheng Wu. Finite element analysis of the heavy semi-trailer frame $[\mathrm{J}]$. The technology of vehicle and power. 2004.04

[6] Hongfei Liu. Mechanics of materials [M]. Beijing: Higher Education Press.2004.01.

[7] $\mathrm{Da} \mathrm{Xu}$. The structure and design of the special automobile [M]. Beijing: People's Communications Press, 2008.

[8] Weiqing Wang. Strength analysis of semi trailer based on finite element analysis [J]. Journal of Qingdao Institute of science and technology. 2010.10 .

[9] Hongqi Jiang, Jibin Ding. The dynamic analysis of the semi-trailer frame based on ANSYS [J].2011.02.

[10] Zhengkun Zhai, Junjie Cui, et al. The finite element modal and harmonic response analysis of the Gooseneck type semi-trailer frame. Journal of Gansu Agricultural University [J]. 2014.04. 